\title{
TEACHING SEMANTIC ETHNOGRAPHY TO ARCHITECTURE STUDENTS
}

\author{
Galen Cranz \\ Department of Architecture, \\ University of California Berkeley \\ galen@berkeley.edu \\ Georgia Lindsay \\ Environmental Design Program, \\ University of Colorado Boulder \\ georgia.lindsay@gmail.com \\ Lusi Morhayim \\ lusimorhayim@gmail.com \\ Hans Sagan \\ Urban Design Program Coordinator, \\ Academy of Art University \\ hsagan@academyart.edu
}

\begin{abstract}
Learning about human behavior, cultural diversity, and user perspectives are all part of the NAAB-required curriculum for educating architects. Beyond that, these skills help architects compete in a global and diverse world. Semantic ethnography offers a method for understanding the user perspective in cultural settings. We present a research and design project centered on semantic ethnography as a way to teach architecture students about how to design for user groups. A survey administered to two years of students indicates that this project is indeed helpful for teaching students about how to find and listen to the user perspective.
\end{abstract}

Keywords: Design pedagogy; Ethnography; User perspective; Teaching architecture

\section{INTRODUCTION}

The latest 2014 National Architecture Accrediting Board (NAAB) criteria streamline and distribute social criteria through the five values that all architecture programs have to demonstrate. Since NAAB does not want to specify these values in a way that would homogenize programs, programs need to share information about the different ways that these values are translated into student performance outcomes. Accordingly, this paper shares our experience teaching "Social and Cultural Processes in Architecture and Urban Design" is a core course at the University of California, Berkeley that incorporates human behavior, cultural diversity, and applied research into architectural education. It introduces key concepts in person-environmental studies, demonstrates how these concepts vary by subculture, teaches programming and evaluation research methods, and promotes thinking critically about the values embedded in design. Students read a wide selection of articles, chapters, and books about theory, methods, and various building and place types with attention to variation by American cultures. One of the two major assignments in this course is an individual, original "semantic ethnographic" research project that leads to redesign of an existing place based on data gathered from the insiders point of view, bolstered by library research, representing the outsider's view.

In Boyer and Mitgang's 1996 report on the state of the architecture profession, Mitgang states that "architecture education centers...on preparing future architects capable of designing 
sturdy, beautiful, and useful structures that serve users, strengthen communities, and enhance the environment" (Mitgang, 1996, xi). In so doing, they echo the Vitruvian principles of building (as paraphrased by Henry Wotten) as commodity, firmness and delight (Vitruvius \& Morgan, 1960). Firmness refers to a structure which supports itself, bears loads, protects from the elements, and is made to last. Delight refers to aesthetic experience including the sensation of elation and inspiration that comes with perceiving a building's form, elegance and art. Commodity refers to social purpose, the capacity to accommodate use, and to sustain social action. Then, to update Wotten and Vitruvius both, we could say that the three pillars of Architecture are Structure, Aesthetics and Social Function.

Salama (2008) also has three areas of architecture, calling it "in tension between reason, emotion and intuition," asserting that architectural education should focus on supporting students' abilities to "conceptualize, coordinate, and execute the idea of building" (p. 100). Responding to these three areas requires comprehensive knowledge and also understanding knowledge production, and thus design education should focus on both "critical inquiry and knowledge acquisition and production" (Salama, 2008, 101). In architectural education, the term function often refers to a specific aspect of architectural design. For many architects, function means the right size for each space, how spaces come together, circulation between those spaces and organization of architectural elements within each space. In the context of social aspects of environmental design, function is a much broader term that includes all psychological, social, cultural aspects of architectural design. Function comes as a product of use by and usefulness to users. In this sense, function is user-centered. In order to understand social function, one must understand the social context or the culture from which the function arises.

However, architecture students have not typically been exposed to techniques for understanding cultural differences, and social science is taught as a series of precepts instead of as a method (Salama, 2010). Similarly, scholars studying space and the uses of space, especially spaces of a specific sub-culture, use ethnographic methods (Brown, 2007; Doxtater, 2005; Nayak, 2010; Yiftachel \& Yacobi, 2003). Anthropological methods have been used in the study of the history of architecture, but there is little ethnographic research into contemporary architecture (Cranz, 1974). The ethnographic method presented here fills this gap. We are using ethnography as a method to understand user perspectives on the uses and meanings of space. While semantic ethnography is the primary focus of the data collection, we also ask students to note their own observations and conduct a precedents and literature review.

Ethnography is the description of a culture in its own terms in real settings. Of all social research methods it is the most sympathetic with the needs and preferences of architects who want information about the context of the design problem without being limited creatively. For decades Galen Cranz has championed semantic ethnography as the best way to bring qualities, not just quantities, into social research for architectural design. Emphasis on qualities leaves the architect room for finding distinctive physical expression of those qualities. Also called cognitive ethnography, semantic ethnography relies on what people can tell you about the nature of the world they live in. It is less time demanding than participant-observation, a technique that requires becoming one of the group under study, and is far more revealing that observation alone. The recent popularity of ethnography in the study of human-computer interaction relies more on ethnography as a way to observe behavior in natural settings. In contrast, semantic ethnography relies more heavily on learning the categories of speech and thought that people use to give meaning to their worlds.

Understanding cultural differences is an important tool for designers, and one that has sometimes been neglected in studio classes, which educators and theorists have accused of alienating women and students of color (For examples, see Anthony and Ahrentzen, 1993; Crysler, 1995; Groat \& Ahrentzen, 1996; Groat and Ahrentzen, 1997; Moore, 2001; Rubbo, 2001; Stevens, 1998; Willenbrock, 1991). Others defend studio practices as a requisite and unique experience, one in which students learn to think about design (For examples, see Dorrian \& Hawker, 2003; Frank, 2008; Wheelwright, 2004; Westfall, 2008). In this paper, we expand studio 
practices to offer an additional educational experience for students. The method outlined here can be applied to the studio model of design education as well as to education on programming and user experience design.

Since the 1970s, the emphasis on social and cultural issues has declined, and especially since the advent of CAD; with the seductiveness of digital designs and previously unbuildable forms, Schuman notes that it has "been difficult for a socially based architecture to hold its own in the competitive world of the design studio" (Schuman, 2006, 8). A somewhat ambiguous set of changes has occurred regarding social factors in NAAB criteria from 2009 to 2014 . The executive director has explained that the organization wanted to streamline the long lists of student performance criteria by eliminating redundancies. After a long three-year process involving the consultation of about 10 professional associations of those in architectural education, NAAB identified five subject areas that they felt were broader than performance outcomes and therefore identified them as values-- critical thinking and visual representation; building practices, technical skills and knowledge; integrated architectural solutions; and professional practice. Since 1949 the organization has committed itself to helping the nation's architecture schools produce equally competent graduates without dictating the number of semesters in any given subject. Therefore, they reduced (by generalizing) the number of student performance criteria that flowed from the five basic values. NAAB claims that they hve redistributed the social and cultural criteria rather than eliminated them. However, some critics feel or worry otherwise.

Several items in NAAB's 2009 Student Performance Criteria related to environment and behavior studies' literature and methods and used to be an accreditation requirement. However, in NAAB's 2014 criteria some of those important items are either less pronounced or totally eliminated. For instance, while previously "A.9. Historical traditions and Global culture" explicitly listed the word tradition, the new criteria under "A.7. History and Culture" omits that. Another example is that architect students may be held responsible for Access for disabled populations, but not for designing in a way to meet various cultural and behavioral needs of differing populations.

The new criteria may be interpreted as indicating that an understanding of cultural diversity is adequate, while the additional step of possessing the skills to translate this into design solutions does not a requirement. "A.11. Applied Research," which was defined as "Understanding the role of applied research in determining function, form, and systems and their impact on human conditions and behavior" is one of the eliminated items from the criteria. Hence, onsite research that would specifically inform user-centered design is no longer deemed necessary. A whole section of "C: Leadership and Practice" that related to environmental and behavior studies closely is dissolved into other items in the new criteria. For instance, "C.3 Client role" and "C.9. Community and Social Responsibility" that were part of 2009 criteria separately are now considered a business and legal issues in 2014 requirements under "D.5. Legal Responsibilities: Understanding the architect's responsibility to the public and the client as determined by regulations and legal considerations involving the practice of architecture and professional service contracts." "C.2 Human behavior," which was already vaguely defined in 2009 criteria is not mentioned as separate criteria at all. Previously "C.8. Ethics and professional judgment" criteria incorporated social, political and cultural issues. The new criteria limits "Professional ethics" with the requirements of AIA code of ethics, and does not mention social, political and cultural issues in a broader sense.

Such institutional change bears close observation to see if "a thousand flowers bloom" as NAAB hopes, or if it allows programs to neglect instruction in social-cultural factors, and eventually leads to a cultural shift that allows architects to feel less responsible for creating spaces that serve community, cultural, and behavioral needs. Understanding clients and empowering them, using onsite research as a basis of design can never be over emphasized. Because the new NAAB criteria do not specify social and cultural issues in regards to design, it is all the more important for academics to set their own standards through their course design. 
Many societies have a cosmopolitan character, or multiple subcultures living closely together. This is especially true for American society. In addition, an ability to attend to social and cultural differences may also help students cope with a global economy, one in which architects are increasingly called upon to design for cultural difference. Luckily, students need not travel the globe to learn how to understand another cultures: "students who are knowledgeable about the experiences of other American cultures are better prepared to participate creatively in our changing profession and society" (Davis, 1993, 36).

How best to teach architecture students is a vibrant and controversial topic (Salama \& Crosbie, 2010), and a variety of approaches address the issue of how best to teach design-and even what good design looks like. One solution is to pair studio and seminar classes to create a hybrid class (for an example, see Bendiner-Viani \& Maltby, 2010). However, such multi-class approaches are not always possible. Salama (2008) identifies a significant gap in the literature on how to introduce real-life issues in theory and lecture courses. Many educators call for real-life experiences (Salama 2008), but how to incorporate the real world into the classroom has not been answered, although books and journals have been devoted to the subject (for examples, see: Nicol \& Pilling, 2000; Salama \& Wilkinson, 2007; also, the International Journal of Architectural Research and the Journal of Architectural Education have both devoted recent issues to the subject-IJAR in 2010 (Volume 4 Issues 2-3) and JAE in 2014 (Volume 68 Issue $1)$ ). In some cases, a course project is focused on one issue, such as wayfinding (Kamal et al., 2010). In other cases, studio instructors interpret the notion of "real-world" to mean a sited project focusing on the materiality of a space (Marinic, 2010). Furthermore, typical architectural education certainly requires site visits or other engagement outside the classroom, but these exercises are often casual and unstructured (Salama 2008, 103); the assignment described here helps structure the time a student might spend on-site, and provides tools for the site analysis that architects must undertake.

The semantic ethnography assignment presented here asks students to go outside their own culture and thereby learn to listen truly and deeply to how their 'clients' use a space. Because perceptions are effected by one's social-cultural experience, we argue for inclusion of user's social and cultural perspectives on design. Architects need social acumen in order to tease out spatial solutions and aesthetic values from social or functional issues. They often design for people who have little or no spatial vocabulary, who speak only in terms of human needs or functional contradictions. Therefore, architects need to understand people at many different levels. We do not view such awareness as a constraint on architectural creativity, but rather a source of inspiration. We would like this attitude to become a standard part of architectural education, which would benefit students-- and the buildings they go on to design.

Some studios, like North Studio at Wesleyan University and Rural Studio at Auburn University explicitly engage the students in real-world projects responding to community requests, some of which are design-build. Here, students explored "architectural concepts while gaining hands-on experience, presented their work to clients, participated in meetings with the local municipality, and tested their ideas beyond the walls of the academy" (Huge, 2009, 66; for a host of examples of real-world studio projects, see Hardin, Eribes, \& Poster, 2006). However, learning about other cultures or American sub-cultures need not be left exclusively to the studio experience; students would be better served by having such a hands-on cross-cultural focus integrated throughout architectural curricula.

Our ultimate goal is a balanced education of design students. These students are at the forefront of defining and literally shaping the future of our world. The stakes are high. All of us inhabit or use buildings. Design education is a rich site of transformative possibility, with practitioners having a direct (and sometimes unwitting) impact in the daily lives of the users of their structures. This impact, depending on the specifics of the site designed, is felt at least to some degree by all social classes, all races, all genders, all users. Architecture is praxis in the Gramscian organic intellectual tradition: a direct, informed intervention into material lives of users. When students become professionals, they will occupy the privileged position of being experts, 
trusted to understand how their buildings work and responsible for their creation's function. Thus, this paper is part of an effort to reassert the importance of emphasizing for students the social effects of their designs, and to sketch a way to enable students to develop that power in concert with their clients and users through interactive ethnographic research.

\section{ETHNOGRAPHY PROJECT OVERVIEW}

For several decades Galen Cranz has taught Architecture 110AC: "Social and Cultural Processes in Architecture and Urban Planning." (The AC designation is for courses which have met University of California, Berkeley's requirements for teaching subjects from the perspectives of at least three American cultures.) The course is designed to expose students to a range of social science methodologies in conjunction with direct experience in the field, culminating in original student research and design. We offer a step-by-step introduction of the ethnographic research, a project that takes students outside the classroom, interacting with people from outside the students' own culture, and that requires research and writing skills beyond what is normally required in studio. We conclude with results of anonymous student course evaluations from 2009 and 2010 in order to give evidence about the influence of ethnographic research knowledge on students' design education. This course incorporates articles and exercises from a variety of methodological viewpoints, while the ethnography project focuses on one multi-faceted technique. Students conduct ethnographic research on an actual location that is easily accessible to them for semester long visits and they redesign this building or outdoor site based on their research. The course is designed around a workbook inspired by Spradley and McCurdy's 2004 book on ethnographic research. The workbook itself is a guide to the ideas behind and process of semantic ethnography, offering students tools and examples on how to develop their own ethnographic projects through understanding the user experience of space.

The concept starts from the standpoint that complex societies do not have homogeneous national values and knowledge. Instead, smaller groups, microcultures, share knowledge. We have added the term "sited" to the anthropological term because microcultures can exist independent of space, whereas in a sited microculture, the group members define themselves partially through and within their relations to their site. Most groups exist in a physical setting, but social scientists do not foreground the environment as environmental designers do. Designers understand that social activity and site interact, each producing the other. The project is broken down into seven distinct parts completed throughout the semester.

\section{Part I: Selecting a Sited Culture}

Students choose a single sited microculture. Ideally, the student will choose a small sited microculture from a culture unfamiliar to them We advise the student's choice; a student who chose a transit station as a site would have considerably difficulty in finding a shared set of meanings amongst users of the site, whereas a decades-old teen music center produces a much more well-defined sited microculture. This provides the student the opportunity to approach the sited microculture as a naive outsider to the sited microculture's unique practices and spatial engagement. Students have chosen a vast variety of sites. Local coffee shops and other eating establishments, places of religious practice, ethic community centers, and art schools have been popular choices. More unusual choices have been tattoo parlors, local hot springs, a semiabandoned rail station, and a mobile dance studio. Once students have chosen their site, we ask them to do basic site research, take photographs or draw any diagrams they feel will help them, and us, understand the site.

Based on these initial informal observations, the students propose their suggestions for improving the site. Redesigning the site at the beginning is important because it creates a baseline for comparison later. Without it students think that their final redesign is what they would have done from the beginning. They have a written record for how much their thinking has changed between their initial redesign and their final redesign that emerged after understanding 
the insider point of view through ethnographic study. We ask students to describe the site verbally as well as provide relevant images and diagrams, when they describe and justify their redesign. Moreover, since our course always includes some non-design students, this initial phase of the project gives them a chance to think like designers regardless of their level of skill at visual representation. It is particularly rewarding to hear the students critique their initial work at the end of the semester; it is as if they view their sites with entirely different eyes.

\section{Part II: Acquiring an informant and semantic interviewing}

Next, students approach someone familiar with the site to act as an informant. This builds on observation skills from the previous section, as discovering who will be most familiar with a place requires familiarity with that place and the activities of the people within it. Students should find an informant who knows a lot about the student's chosen site, but also someone with whom they feel they can establish rapport for repeated interviews. They turn in a description of who they have chosen, and why, role of this person in the sited culture and the rapport between the informant and the student.

Semantic ethnography does not rely on previously established questions to conduct interviews. Instead, it has its own special sequence for collecting information. One begins by asking the informant to give a tour of the site. Students pay attention to the words their informants are using as they describe their sited culture. They record the terms used in the introduction to the site and ask for further clarification of each term. This aids students in understanding the sites as their users do. Because many architects do not get to visit sites, teaching students this method of deep listening affords them the opportunity to learn how clients think about their own activities. We teach semantic ethnography as a way to give future designers an important practical tool that they can use in professional life. Part II establishes talking with people as a data collection technique and gives students a chance to begin to practice a special interviewing skill that relies on close listening. Also, the students get the user's perspective. Unlike conventional interviewing with a prepared list of issues or questions, in this project, we especially ask students not to have any predetermined questions. Rather we want them to have complete understanding of their sited microculture with no bias that comes from their architectural education and the questions architects might ask.

Much of the education that studio provides is by necessity insular; students are used to a hearing a professional's perspective rather than user's. In practice, users who do not necessarily speak a language of design still have opinions about the space. This encourages the student to engage with the informant on the terms of the specific culture of the site itself. They are asked to accept as true the social reality that their informant presents to them. These carefully "unstructured" conversations follow up on each term the informant uses.

\section{Part III: Developing Taxonomies}

After students collect semantic data, through at least three interviews about their informants' view of the site and the sited culture, we ask them to create a graphic taxonomy based on that data. Creating a visual diagram of the insider point of view taps into the students' visual design skills, and helps them tackle the problem of how to convey complex semantic ethnographic information in an understandable, objective, and interesting way through graphic representation (Figure 1). This portion of the project often requires considerable instructor involvement and guidance. Few are used to seeing mere conversation as revealing the categories and underlying structure of thought. We ask the students to watch for particular organizations of thought in their informants and their site users. Once the students assemble a list of terms that their informants or interviewees use, they are asked to arrange them in a taxonomic order starting with the most general term, known as the cover term. Students discover the relations between the terms that their informants use and group them into a visual display of their relationship in a map of 
categories. Typically, terms cover three areas: people, activities, and spaces. Other categories have been feelings, perceptions, qualities, histories or visions/goals.

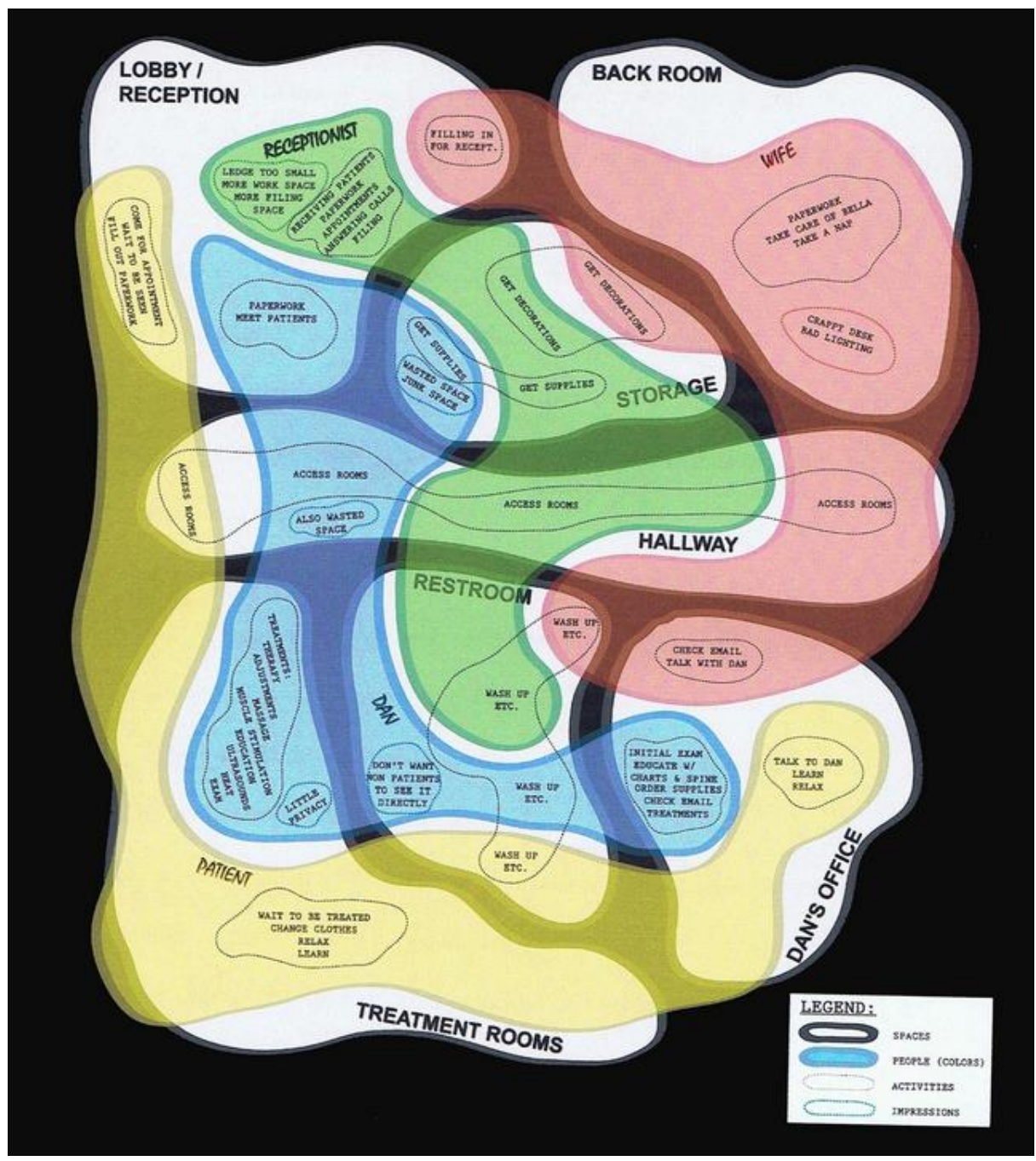

Figure 1: A student's taxonomy for Diablo Sports and Spine Center creatively juxtaposes categories of spaces, users, activities and interconnections between them in the same graph (Source: Mark Mattson, Fall 2008).

Students prepare a draft taxonomy and to show it to their informant, cross checking for validity and additional clarification. Sharing their taxonomy reinforces students' positive relation with their informant; the informants are invariably impressed and flattered to see students paying so much attention to their words and worldviews. This aids the project as a whole as it maintains rapport with users and includes their feedback into the analysis and redesign process.

\section{Part IV: Literature Review}

After gaining a user perspective, students conduct a literature review and present their findings in an annotated bibliography. This provides an outsider's point of view that both balances and values the contributions of the user's point of view. Sources include precedents regarding how other designers have solved whatever spatial problems the students have uncovered in their investigations. 
We also encourage students to think broadly about their design problem, for example, if their site is a local coffee shop, they should look at the ample research that coffee chains have conducted about how they design and redesign their stores for very specific uses and moods. if their site is a café, and their problem is acoustics, what might research on theaters or libraries have to offer as solutions? Students should research similar but not identical sites, because their specific site is not likely to have been studied by another person, and design inspiration comes from a variety of sources. To use the above example, if the student is studying a local coffee house, they may use texts on local restaurants (to gain insight into local dining cultures), other coffee shops, or even information on coffee production. The student must assess the usefulness of each source to their site and its redesign.

When students struggle with this section, we observe that they have not yet clearly defined the central design problem their informant brought to their attention, or because they are not used to conducting literature reviews for redesign purposes. Some students point out that they are majoring in architecture partially because they dislike writing papers and the research that goes into them. Even though architecture students often have a much more visual learning style than their non-design peers, this assignment is so geared to their project that it does not feel like an ordinary abstract library research paper. Learning to appreciate library research for its insights may build a habit of using studies in person-environment relations and evidence-based design; without it students would continually reinvent the proverbial wheel. Furthermore, many students will go on to careers other than design, or will be one part of a design team, and learning library research skills adds to their toolbox of techniques for learning about the world.

\section{Part V: Programming and Redesign}

Once the students have learned about their site through their own informal observations, carefully unstructured ethnographic interviews, and library research, we ask the students to consolidate/synthesize these emic and etic points of view and employ them to redesign the space. Rather than a simple list of activities, we ask them to think about the qualities of spaces that are needed to accommodate specific needs and patterns they have discovered through social research. Thus, this approach offers a new approach to architectural programming, one that combines drawings, images from precedent examples, modes, feelings and qualities of space with minimum spatial requirements.

For all our students, design and non-design majors, we stress that evaluation on this project is not based on quality of the drawings or the aesthetic quality of their design, but rather how well their designs respond to their newly gathered information. This portion of the project is evaluated on the students' comprehension of the gathered data and its translation into spatial form that acknowledges and accommodates the needs and aspirations of the users. Their justification of how they arrived at their re-design choices demonstrates to them how research on person-environment relations can influence designs positively.

\section{Part VI: Communicating with the Public: Poster}

The last two parts of the assignment are concerned with the presentation of ideas. In Part $\mathrm{VI}$, students are asked to present their final redesign visually in a single poster of $24 \times 36$ inches. We ask the students to present not only their re-design, but also the justification for how they arrived at that design, including the taxonomy that they created based on the informant's view of the space. Thus, we expect them to present drawings of the new space, as any design studio would have them do, as well as the causes of those design interventions. We ask for an argument, a cause and effect relationship, to be apparent on their poster. Although this is not an easy task, we consider it an important design challenge for students who communicate visually. Handling text appropriately - color, font size and style, amount and distribution of text, its relation to images and diagrams - on a poster board is a big part of this assignment (Figure 2). 
As brevity often requires a deeper understanding than lengthy explanations, students sometimes complain about the space limitations. However, learning to present ideas succinctly is an important task for students, especially students whose careers may involve community presentations, design competitions, or sending drawings to clients across the world.

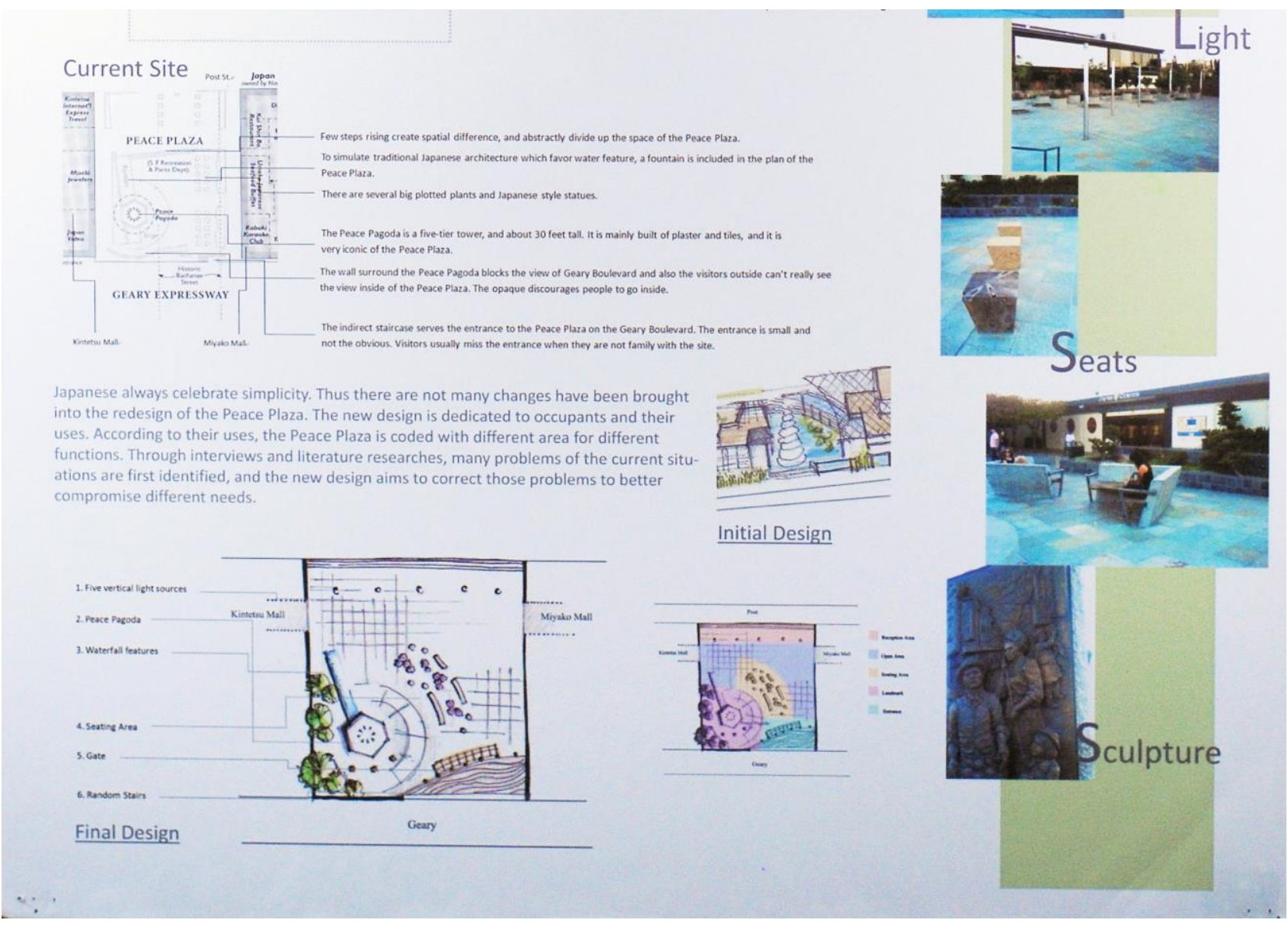

Figure 2: Student poster design for the ethnography of San Francisco Japan Town Peace Plaza (Source: Stella Liang, Fall 2007).

\section{Part VII: Final Report}

The last step is to synthesize learning and produce a final report, formatted more or less according to standard social science practice. That is, these final reports have: an introduction, where students introduce the site and the project; a methods section, where students lay out the three methods they employed in their research on the subject, namely, informal observation, semantic ethnographic interviewing, and archival or library research; a findings section, in which students present and explain their taxonomy and their final redesign, both visually and verbally; and a conclusion, in which they comment of the differences between their initial redesign and their final, post-research design. This is an important measure of their own learning experience. In the conclusion, we also ask students to address how the different methods influenced their final design, and how they can employ similar methods in future projects. Most of the report is drawn from earlier sections, and although we expect 15-20 pages including drawings, producing a substantial paper is not an onerous task, even for the least text-oriented undergraduates, because they have already written most of the material. For the final report we ask them only to reorganize it, respond to their Graduate Student Instructors editorial suggestions, refine language, and be sure to use correct bibliographic entries. 
By preparing this final report as an academic paper they are learning another option for presenting research. Part $\mathrm{VI}$, the poster, is one way to present research, and a common method in the field of architecture. Additionally, we want students to be familiar with social science literature and presentation methods. By requiring students to present their own research in this modified standard format, we give them access to understanding what goes into any research papers they might read when investigating future projects or conducting future literature reviews; they understand the format because they have had to produce it. For those who choose to go on to graduate school or professional work in areas other than design have another tool available for presenting their ideas. The final report gives the students some experience in presenting a detailed argument justifying their design decisions.

Further, writing a cohesive final report can provide a sense of accomplishment; students are often surprised at how much they now know about their site and the culture it holds, and about how much they can write easily even at the end of the semester when other course work is demanding and they know so much about their own site that they might feel daunted by all its nuances and complications. They end up with a piece of original research, unusual for undergraduates, that can be submitted for undergraduate research contests and contributes to their portfolio for when they apply to jobs or to graduate school.

\section{STUDENT RESPONSE TO THE PROJECT}

At the end of the 2009 and 2010 semesters, we asked students to give us feedback on the ethnography project. The survey was a mix of Likert-scale and open-ended questions. As this survey was in addition to the departmental course evaluation forms, students were given $1 / 2$ point extra credit for participating. An online survey tool (surveymonkey) was used to collect responses from students. (Graduate student instructors collected the survey results only after grading student's final projects in order to assure that student can respond to the year-end survey honestly.) We sent emails with links to the survey and the survey remained open until the day after the final report due date. Out of a total of 265 enrolled students in 2009 and 2010 combined, 200 students responded to the survey. (We combine the two years survey results to overcome possible effects of year-specific graduate student instructors).

We asked students to rate how the ethnography project helped them learn some aspects of the design process, such as understanding user's perspective, listening to clients, developing a program, and evaluating an existing environment/space. On a 7-point Likert scale (7 being most helpful) students reported that ethnography assignment was highly helpful on these three aspects of design, with an averages consistently over 5 and the mode being 6 for all three questions (Table 1).

Table 1. Influences of the ethnography assignment on the design process.

\begin{tabular}{|l|l|l|l|l|}
\hline $\begin{array}{l}\text { How well ethnography } \\
\text { project helped you learn... } \\
\text { (with 1 being not at all and } \\
7 \text { being most helpful) }\end{array}$ & $\begin{array}{l}\text { to take the user's } \\
\text { point of view }\end{array}$ & $\begin{array}{l}\text { to listen to } \\
\text { clients }\end{array}$ & $\begin{array}{l}\text { to develop programming } \\
\text { for a building or any } \\
\text { other kind of space }\end{array}$ & $\begin{array}{l}\text { to evaluate an } \\
\text { existing } \\
\text { environment }\end{array}$ \\
\hline Mean & 5.62 & 5.49 & 5.21 & 5.66 \\
\hline Median & 6 & 6 & 5 & 6 \\
\hline Mode & 6 & 6 & 6 & 6 \\
\hline
\end{tabular}

In addition to these forced-response questions, we asked three open-ended questions of the students. First, we asked them to reflect on how they will incorporate what they learned into future practice either in school or beyond. Out of 181 responses to this question, seventy-six comments demonstrated a commitment to incorporate the user's perspective in the future. These comments ranged from the mundane, "I will always record client meetings" to loftier ambitions, such as "I will consider the different user groups that will be using the space instead of focusing solely on my personal preferences." Twenty-seven students remarked that they would incorporate 
evidence into their designs in the future, referring either to evidence in general, for instance "I really enjoy doing research and using that for design will help me in the future", or specifically to the techniques we taught in class, for instance "...the skills to listen to people during interviews. I believe that this skills can be used even during normal conversations to further understand beyond the verbal level" or "I will incorporate what I learned by observing more of my surroundings and asking questions to people linked to those surroundings. I am no longer shy about asking simple questions and listening word for word from other people."

Nine students' comments compared architectural studio courses with the ethnography assignment. Students indicated that they want to, but cannot imagine finding opportunities to, incorporate social research into their studio courses, even though in their future practice they would like to use social research to develop the design program, including one student who said, "most of the school design projects I've worked on did not have a client to perform ethnographic research on...not sure what type of projects will be assigned in the future. I would love to do more research like this."

Only five students gave negative feedback to this question, saying things like they fail to see the worth, it was not very helpful, or pointing out that the assignment did not apply to their field (we have students from other departments, not only architecture students). The other 64 comments not called out here were generically positive, ranging in topic from learning about programming to aesthetics, with two students specifically saying they will use a version of the taxonomy as a design tool in the future.

Second, we asked students to comment on how these techniques may have changed the way they understand buildings. Again, the majority of the students (46 of 179 who responded to this question) talked about the importance of the user or user perspective to understanding buildings, saying things like, "Buildings are for people not paper," and, "I would say they did not change the way I understand buildings but instead changed the way I understand the people who use them." Eighteen talked about the importance of function, sixteen addressed the importance of culture in understanding buildings, and fourteen students indicated that after the ethnography assignment that they had a deeper understanding of the complexity of buildings. The rest of the comments defy categorization, but indicate a breadth and depth of learning far too complex to summarize here. Three examples will have to suffice for indicating the types of comments received: "This has helped me to begin to feel confident about insisting that buildings cannot be seen to exist in isolation. They must be considered as interdependent parts of larger ecosystems," and, "the interviewing process showed me the dynamic relationship between buildings and people, each adapting to each other. Buildings and their programming are not static and need to be continuously modified to meet the people's changing needs," and finally, "apart from my leisure readings I didn't really know anything about architecture and design before this class, I feel these techniques gave me a good foundation to my understanding of buildings and spaces."

Finally, we asked students what other feedback they had for us about the project. Out of 140 responses, 59 said the project was fun or interesting or otherwise indicated a positive reaction. Forty-six were specific suggestions about timing in the semester, grading, or other tweaks to improve the project. Eight comments indicated confusion on the part of the student at some point during the project and 13 were general criticisms. Ten students said the project was too much work. This is an important point. Only $5 \%$ of students thought that a project that required multiple 5-page papers throughout the semester, hours of on-site interaction and that resulted in a 20-30page final paper was too much work. Of all the responses indicated here, this might be the best indicator that the students found the time invested worthwhile.

Based on these survey results we conclude that semantic ethnographic project and its different research methods reshaped students understanding of design and building processes. At least 76 students stated that after this assignment aesthetic appearance is no longer their only design criteria. Student comments demonstrate that they acknowledge the importance of user needs and the interrelationship between people and the buildings more than before. Especially 
the semantic interview and informal observations helped them understand and interpret user behavior. Comments indicate that learning by doing (i.e. applying each research method in an actual site) is an effective way of teaching how to do research, rather than talking about principles and techniques.

\section{CONCLUSION}

The survey indicates that students indeed learn to listen to clients and to take the user perspective. From the student perspective, this project is most effective at helping them learn to evaluate an existing environment and to take the user's point of view. We emphasize again that the techniques used to gather the user's point of view work in cross-cultural settings-indeed, it is drawn from anthropology methods for understanding cultures other than that of the researcher. In this way, we are supporting design studios by giving future architects ways to understand the needs of clients from across the globe. We do not have long-term data about the percentage of students who truly go on to incorporate these habits into practice, but we do have some anecdotes of students inspired by this project, including one who informed us on the survey that he or she plans on majoring in Social Factors in Architecture, and some students who have pursued a $\mathrm{PhD}$ in the subject after taking the course. Some practicing professionals have reported decades later that they still use this technique of active listening that they learned as undergraduates.

The benefits of this pedagogy extend beyond the reaches of the academy. Over the course of the semester, students build long-term relationships with the people at their sites, becoming more fully engaged with the needs of the users of their designs, and more connected to the communities they serve. As the semester wears on, they become even more curious about the site and more gracious in accommodating the sited culture's world view. Students finish the assignment with an understanding of a few methods for learning about site-specific personenvironment relations, as well as ideas for how these methods could be applied in their own design work. They also finish the semester with an original research project report, and an addition to their design portfolio. Especially as NAAB criteria now redistribute cultural and human into multiple contexts-and as evidence-based design becomes the norm in hospital and educational settings-experiences such as this one can help students differentiate their portfolio in a competitive market.

Design students' career opportunities will expand if their education gives them the time, impetus, and skills to incorporate such qualitative social science research methods into their design education. Moreover, the built environment and the field of architecture will benefit from having social concerns incorporated into design because these buildings will provide environments responsive to human needs. The pedagogy we propose offers one way, of many possible ways, to incorporate person-environment relations knowledge and research techniques into architectural education. Semantic ethnography is particularly suited to architectural design because it is qualitative, interactional, not restrictive, and generative.

\section{REFERENCES}

Ahrentzen, S., \& Anthony, K. H. (1993). Sex, stars, and studios: A look at gendered educational practices in architecture. Journal of Architectural Education, 47(1), 11-29.

Bendiner-Viani, G. \& Maltby, E. (2010). Hybrid ways of Doing: A Model for Teaching Public Space. International Journal of Architectural Research 4(2-3), 407-418.

Brown, G. (2007). Mutinous eruptions: autonomous spaces of radical queer activism. Environment and planning 39(11), 2685-2698.

Cranz, Galen, C. (1974). Ethnography and Formal Sociological Theory Contrasted for Teaching ManEnvironment Relations. Teaching Man-Environment Relations (Special Interest Mimeographed publication within EDRA 5). 
Crysler, C. G. (1995). Critical pedagogy and architectural education. Journal of Architectural Education, 48(4), 208-217.

Davis, R. (1993). Writing multiculturalism into architecture curricula. Journal of Architectural Education, 47(1), 30-37.

Dorrian, M., \& Hawker, A. (2003). The tortoise, the scorpion and the horse-partial notes on architectural research/teaching/practice. The Journal of Architecture, 8(2), 181-190.

Doxtater, D. (2005). Living in La Paz: an ethnographic evaluation of categories of experience in a 'new urban' residence hall. Journal of architectural and planning research 22(1).

Frank, M. (2008). The theory of pure design and American architectural education in the early twentieth century. Journal of the Society of Architectural Historians 67(2).

Groat, L. N., \& Ahrentzen, S. B. (1996). Reconceptualizing architectural education for a more diverse future: Perceptions and visions of architectural students. Journal of Architectural Education, 49(3), 166-183.

Groat, L. N., \& Ahrentzen, S. B. (1997). Voices for change in architectural education: Seven facets of transformation from the perspectives of faculty women. Journal of Architectural Education, 50(4), 271-285.

Hardin, M. C., Erives, R. \& Poster, C. (Eds.) (2006). From the Studio to the Streets: Service-Learning in Planning and Architecture. Sterling, VA: American Association for Higher Education.

Huge, E. (2009). Study as a course of practice: The work of north studio at Wesleyan University. Journal of Architectural Education, 62(3), 65-70.

Kamal, A., Doganer, S., Ruvuna, J., Flores, J., Hernandez, E. \& Nishimoto, T. (2010). Wayfinding and Accessibility in the San Antonio Riverwalk: A Model for Urban Design Education. International Journal of Architectural Research 4(2-3), 391-406.

Marnic, G. (2010). Bubble Up: Alternative Approaches to Research in the Academic Architecture Studio. International Journal of Architectural Research 4(2-3), 61-75.

Mitgang, L. D. (1996). Preface: Making the Connections. In E. L. Boyer \& L. D. Mitgang (Eds.), Building Community: A New Future for Architecture Education and Practice (xi). Princeton N.J.: The Carnegie Foundation for the Advancement of Teaching.

Moore, K. D. (2001). The Scientist, the Social Activist, the Practitioner and the Cleric: Pedagogical exploration towards a pedagogy of practice. Journal of Architectural and Planning Research, 18(1), 59-79.

Nayak, A. (2010). Race, affect, and emotion: young people, racism, and graffiti in the postcolonial English suburbs. Environment and Planning A, 42(10), 2370-2392.

Nicol, D. \& Pilling S. (eds.) (2000), Changing Architectural Education: Towards a New Professionalism, Spon Press, London, United Kingdom.

Rubbo, A. (2001). Values and architectural education. Architectural Theory Review, 6(2), 65-80.

Salama, A.M. (2008). A Theory for Integrating Knowledge in Architectural Design Education. International Journal of Architectural Research 2(1) p100-128.

Salama, A.M. (2010) Delivering Theory Courses in Architecture: Inquire-Based, Active, and Experiential Learning Integrated. International Journal of Architectural Research 4(2-3), 278-295.

Salama, A.M., \& Crosbie, M.J. (2010). Design Education: Explorations and Prospects for a Better Built Environment. International Journal of Architectural Research 4(2-3), 10-18.

Salama, A.M. \& Wilkinson, W. (eds.)(2007), Design Studio Pedagogy: Horizons for the Future, The Urban International Press, Gateshead, United Kingdom.

Schuman, A. W. (2006). Introduction: The Pedagogy of Engagement. In M. C. Hardin, R. Erives, \& C. Poster (Eds.), From the Studio to the Streets: Service-Learning in Planning and Architecture. Sterling, VA: American Association for Higher Education.

Spradley, J. P., \& McCurdy, D. W. (1972). The cultural experience: Ethnography in complex society (p. 18). Chicago: Science Research Associates.

Stevens, G. (2002). The favored circle: The social foundations of architectural distinction. MIT Press.

The National Architectural Accrediting Board, Inc. (2009). Conditions for Accreditation. Retrieved from http://www.naab.org/accreditation/2009_Conditions.aspx.

The National Architectural Accrediting Board, Inc. (2014). 2014 Conditions for Accreditation, First Reading. Retrieved from http://www.naab.org/accreditation/2014_Conditions.

Vitruvius, P. \& Morgan, M. H. (1960). Vitrivius: The Ten Books on Architecture. New York: Dover Publications.

Westfall, C. W. (2008). Why the orders belong in studio. Journal of Architectural Education, 61(4), 95-107. 
Wheelwright, P. (2004). Why There is No Such Thing as "The Real World". Journal of Architectural Education, 57(4), 56-57.

Willenbrock, L. L. (1991). An undergraduate voice in architectural education. Voices in architectural education: cultural politics and pedagogy. New York: Bergin and Garvey, 106.

Williams, M. A., \& Young, M. J. (1995). Grammar, Codes, and Performance: Linguistic and Sociolinguistic Models in the Study of Vernacular Architecture. Perspectives in Vernacular Architecture, 40-51.

Yiftachel, O., \& Yacobi, H. (2003). Urban ethnocracy: ethnicization and the production of space in an Israeli mixed city'. Environment and Planning D, 21(6), 673-694.

\section{AUTHORS:}

\section{Galen Cranz}

Professor

University of California Berkeley, Department of Architecture

galen@berkeley.edu

\section{Georgia Lindsay}

Visiting Assistant Professor

University of Colorado Boulder, Environmental Design Program

georgia.lindsay@gmail.com

Lusi Morhayim, PhD

lusimorhayim@gmail.com

\section{Hans Sagan}

Urban Design Program Coordinator, Academy of Art University

hsagan@academyart.edu 